\title{
Erratum to: Coping Strategies for HIV-Related Stigma in Liuzhou, China
}

\author{
Ying-Xia Zhang $\cdot$ Carol E. Golin $\cdot$ Jin Bu $\cdot$ \\ Catherine Boland Emrick • Nan Zhang • \\ Ming-Qiang Li
}

Published online: 29 January 2014

(C) Springer Science+Business Media New York 2014

\section{Erratum to: AIDS Behav \\ DOI 10.1007/s10461-013-0662-2}

Unfortunately, the given names and family names of the first, third, fifth and sixth authors were transposed in the original publication. The author names have been corrected in this erratum.

The online version of the original article can be found under doi:10.1007/s10461-013-0662-2.

Y.-X. Zhang $(\bowtie) \cdot$ M.-Q. Li

Liuzhou Center for Disease Control and Prevention,

Project Office, Tanzhong West Road 1-1,

Liuzhou 545007, Guangxi, China

e-mail: 331044210@qq.com

C. E. Golin

Division of General Medicine and Epidemiology, University

of North Carolina at Chapel Hill, Chapel Hill, NC, USA

C. E. Golin

Department of Health Behavior, University of North Carolina

at Chapel Hill, Chapel Hill, NC, USA

C. E. Golin - C. B. Emrick

Center For AIDS Research (CFAR), University of North

Carolina at Chapel Hill, Chapel Hill, NC, USA

J. $\mathrm{Bu}$

Editorial Department, Journal of Nanjing Medical University,

Nanjing, China

\section{N. Zhang}

Division of Anthropology Studies, Institute for Advanced

Studies in Humanities and Social Science, Chongqing

University, Chongqing, China 